\title{
Calyciphylline D, a Novel Alkaloid with an Unprecedented Fused-Pentacyclic Skeleton from
}

Daphniphyllum calycinum

Shizuka Saito, ${ }^{\dagger}$ Takaaki Kubota, ${ }^{\dagger}$ Eri Fukushi, ${ }^{\ddagger}$ Jun Kawabata, ${ }^{\ddagger}$ Huiping Zhang, ${ }^{\S}$ and Jun'ichi Kobayashi*,†

${ }^{\dagger}$ Graduate School of Pharmaceutical Sciences, Hokkaido University, Sapporo 060-0812, Japan

${ }^{\ddagger}$ Graduate School of Agriculture, Hokkaido University, Sapporo 060-8589, Japan

${ }^{\S}$ Department of Chemistry of Natural Drugs, School of Pharmacy, Fudan University;

138 Yixueyuan Road, Shanghai 200032, People's Republic of China

\section{Supporting Information}

Experimental Section

Figure S1. ${ }^{1} \mathrm{H}$ NMR spectrum of calyciphylline D (1) in $\mathrm{CD}_{3} \mathrm{OD}$.

Figure S2. ${ }^{13} \mathrm{C}$ NMR spectrum of calyciphylline $\mathrm{D}(\mathbf{1})$ in $\mathrm{CD}_{3} \mathrm{OD}$.

Figure S3. ${ }^{1} \mathrm{H}-{ }^{1} \mathrm{H}$ COSY spectrum of calyciphylline D (1) in $\mathrm{CD}_{3} \mathrm{OD}$.

Figure S4. TOCSY spectrum of calyciphylline D (1) in $\mathrm{CD}_{3} \mathrm{OD}$.

Figure S5. HMQC spectrum of calyciphylline D (1) in $\mathrm{CD}_{3} \mathrm{OD}$.

Figure S6. HMBC spectrum of calyciphylline D (1) in $\mathrm{CD}_{3} \mathrm{OD}$.

Figure S7. NOESY spectrum of calyciphylline D (1) in $\mathrm{CDCl}_{3}$. 


\section{Experimental Section}

General Experimental Procedures. IR and UV spectra were recorded on a Shimadzu UV-1600PC and a JASCO FT/IR-5300 spectrophotometers, respectively. ${ }^{1} \mathrm{H},{ }^{13} \mathrm{C}$ and 2D NMR spectra were measured on a Bruker AMX-600 spectrometer using $2.5 \mathrm{~mm}$ micro cells for $\mathrm{CD}_{3} \mathrm{OD}$ (Shigemi Co., Ltd.). Positive-mode ESIMS were obtained on a JEOL JMS 700-TZ spectrometer using a sample dissolved in $\mathrm{MeOH}$.

Extraction and Separation. The leaves of Daphniphyllum calycinum (1.8 kg) were crushed and extracted with $\mathrm{MeOH}$. The $\mathrm{MeOH}$ extract was treated with 3\% tartaric acid $(\mathrm{pH} 2)$ and then partitioned with EtOAc. The aqueous layer was treated with saturated $\mathrm{Na}_{2} \mathrm{CO}_{3}$ (aq) to $\mathrm{pH} 10$ and extracted with $\mathrm{CHCl}_{3}$ to give a crude alkaloidal fraction. The alkaloidal fraction was purified by an amino silica gel column (hexane/AcOEt, 1:0 $\rightarrow$ 4:6, and then $\left.\mathrm{CHCl}_{3} / \mathrm{MeOH}, 1: 0 \rightarrow 0: 1\right)$. The fractions eluted with hexane/EtOAc (3:2) was purified repeatedly by silica gel columns $\left(\mathrm{CHCl}_{3} / \mathrm{MeOH}, 1: 0 \rightarrow 0: 1\right)$ to afford calyciphylline D (1, $2.5 \mathrm{mg}, 0.00013 \%$ yield $)$.

Calyciphylline D (1): colorless amorphous solid; $[\alpha]_{\mathrm{D}}{ }^{24}-25.6^{\circ}$ (c $\left.0.5, \mathrm{MeOH}\right)$; IR (neat) $v_{\max } 1680 \mathrm{~cm}^{-1} ;{ }^{1} \mathrm{H}$ and ${ }^{13} \mathrm{C} \mathrm{NMR}$, see Table 1; ESIMS m/z $456(\mathrm{M}+\mathrm{H}){ }^{+}$; HRESIMS (m/z 456.3452 [ $(\mathrm{M}+\mathrm{H})^{+}$; calcd for $\left.\mathrm{C}_{29} \mathrm{H}_{46} \mathrm{NO}_{3}, 456.3478\right]$ ). 

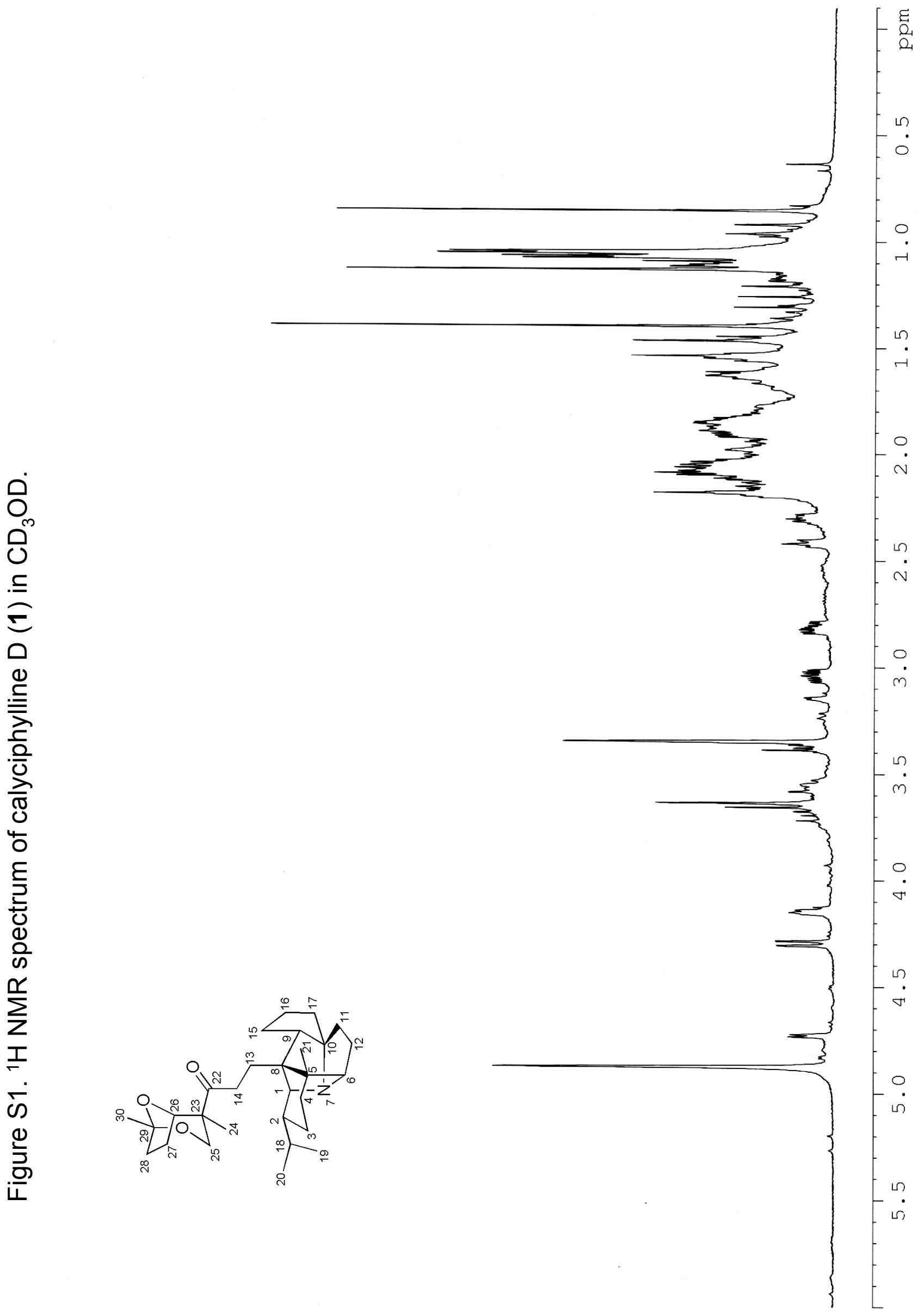


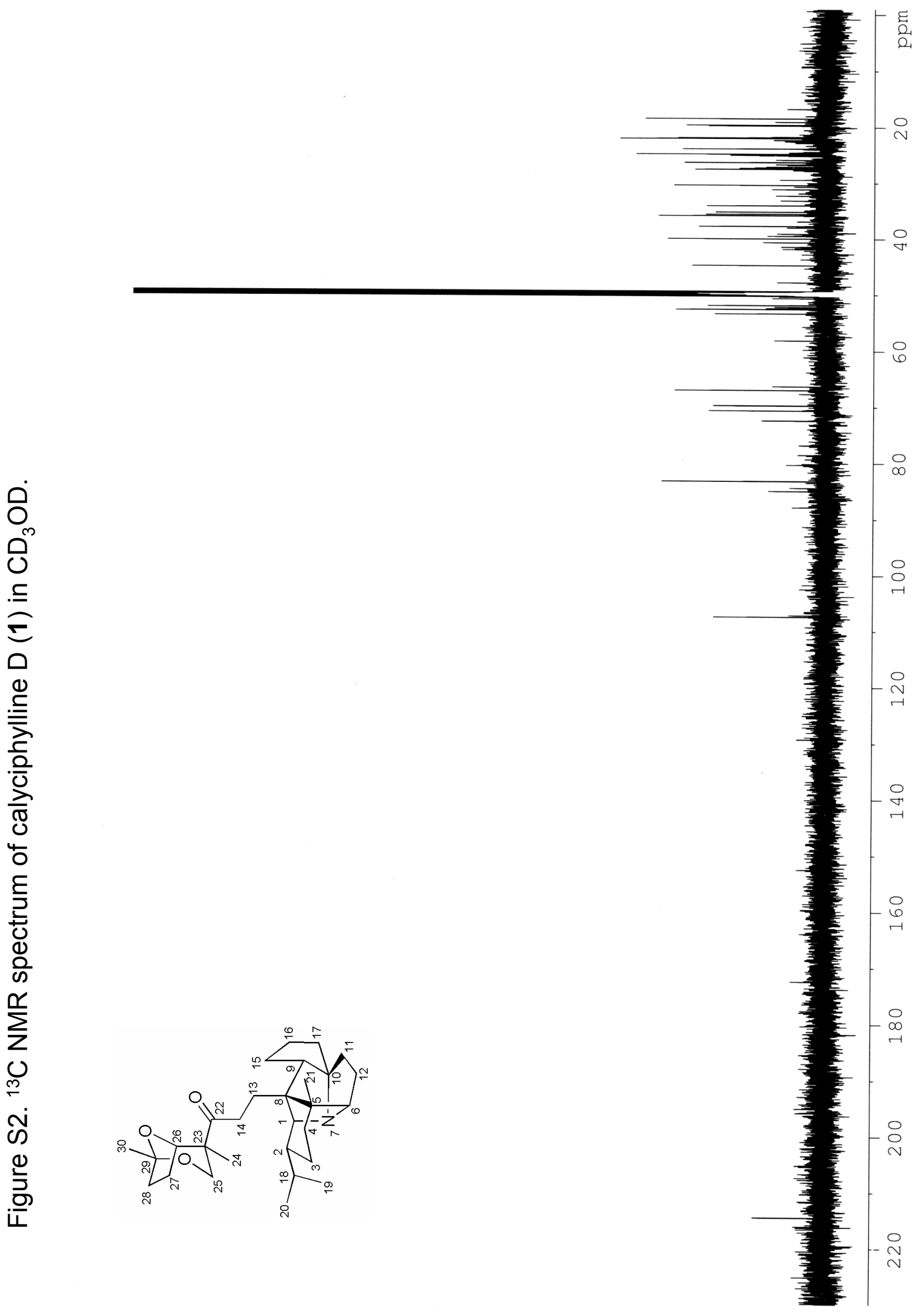




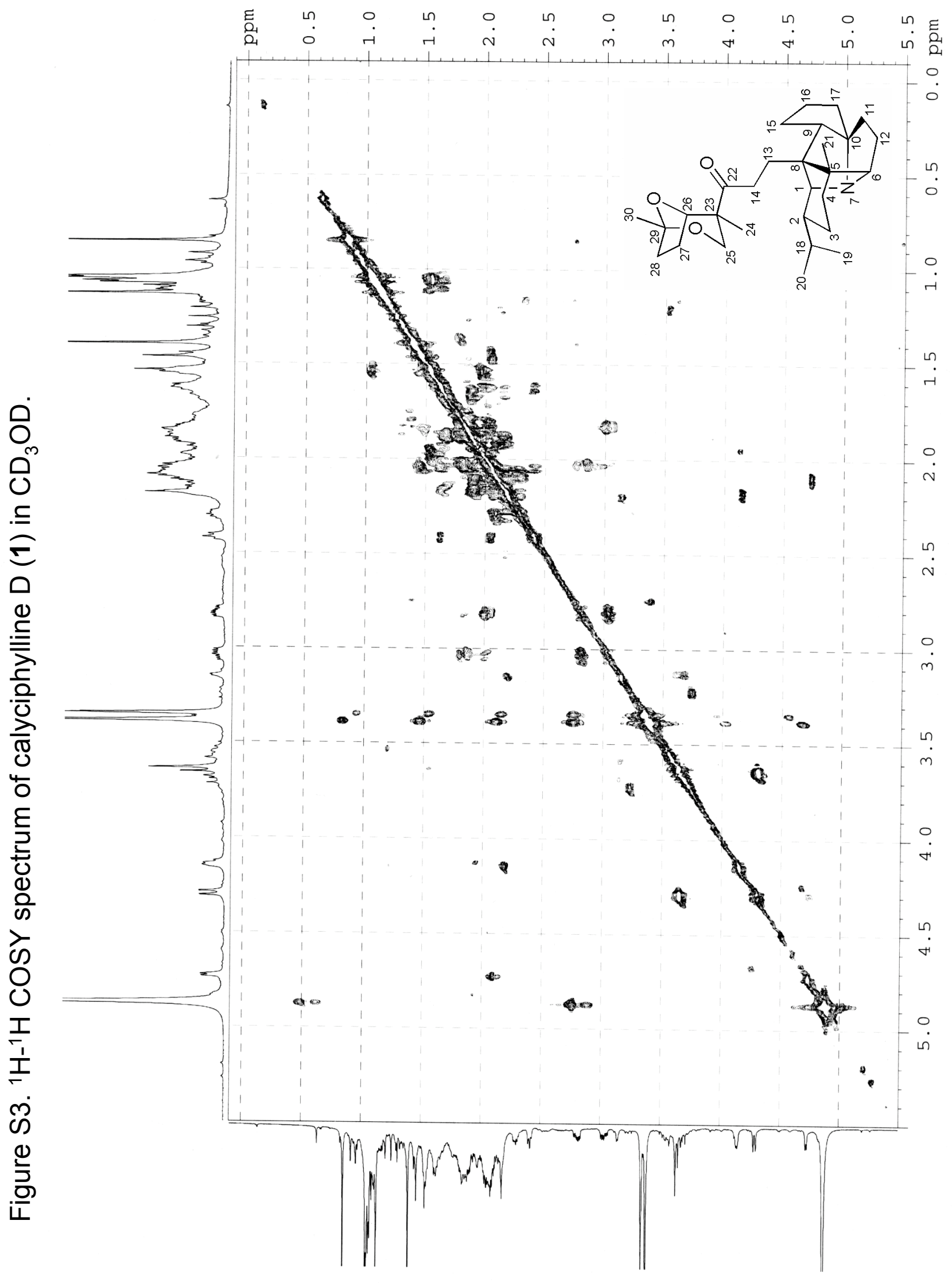




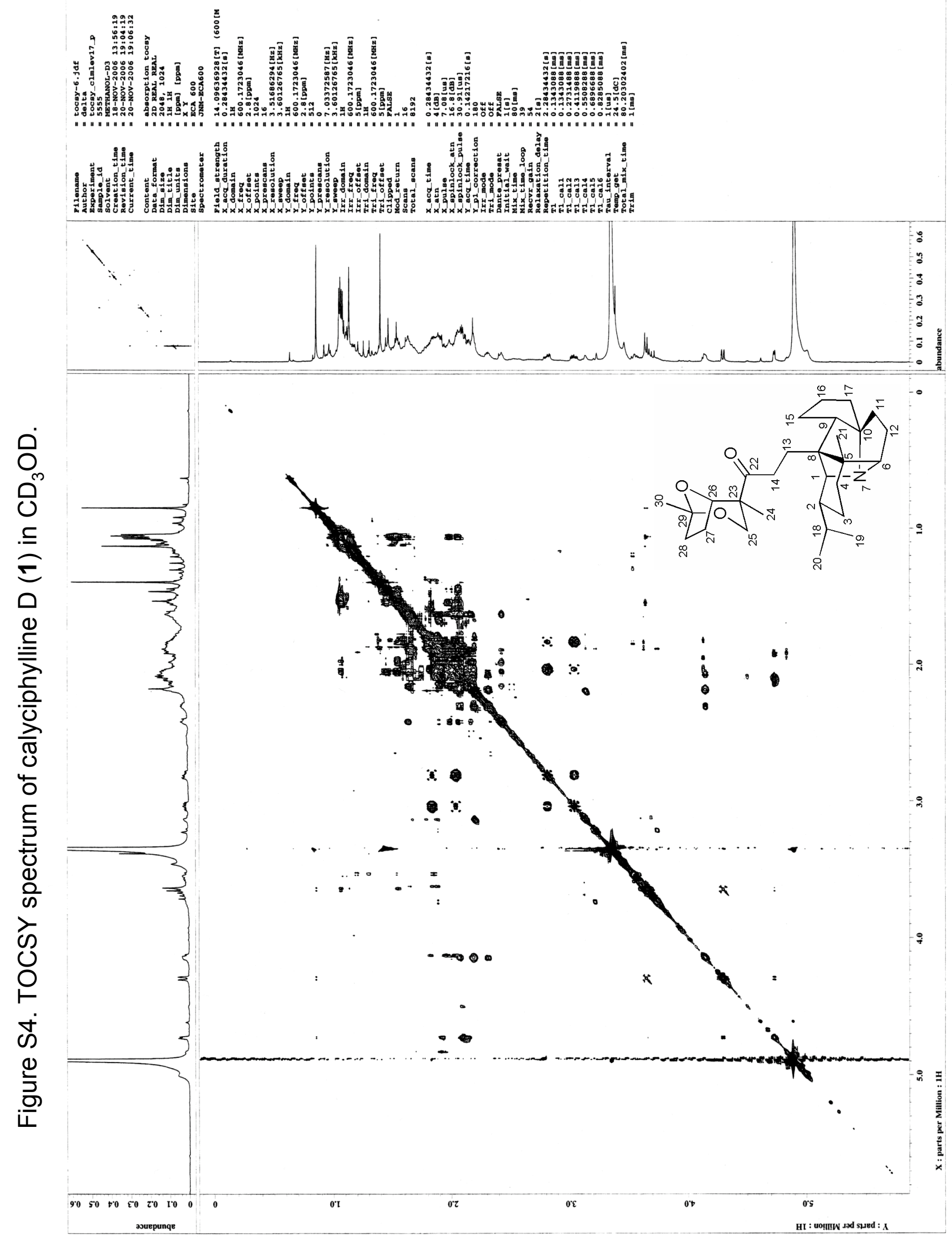




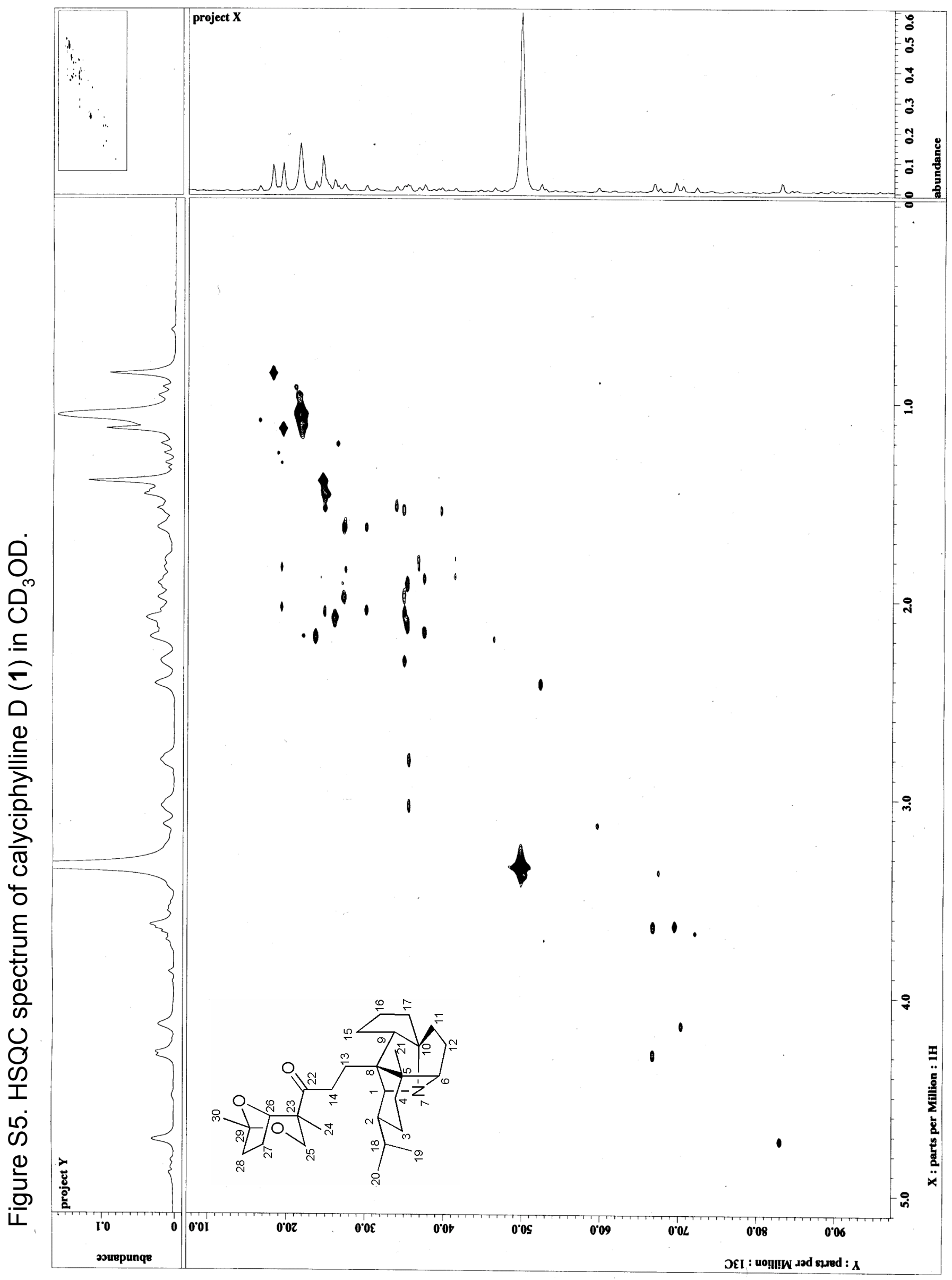




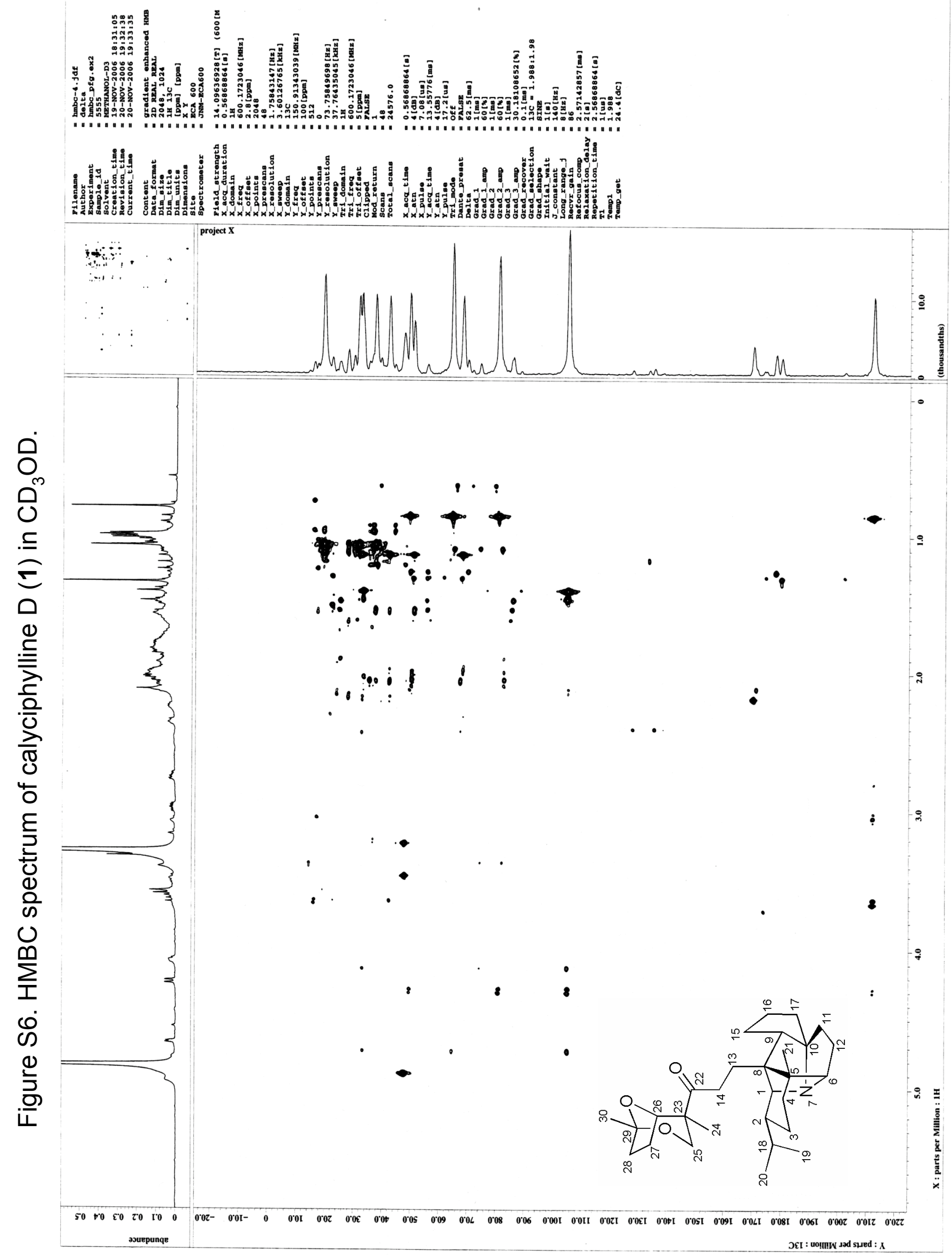




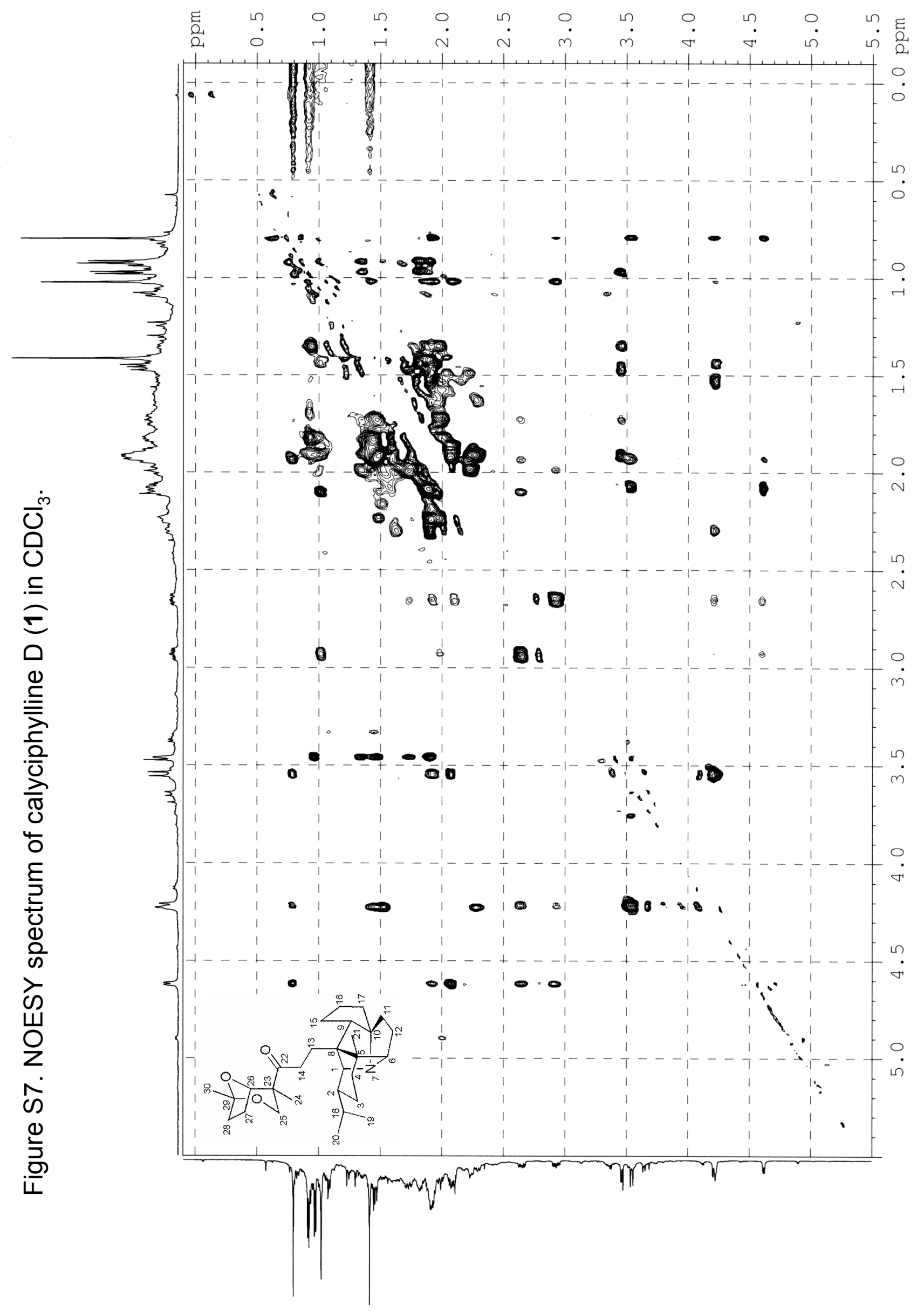

